Available online at www.refaad.com

VMPH 1(2); 2020: 60-69

Research Article

Veterinary Medicine and Public Health Journal (VMPH)

Journal Homepage: https://www.refaad.com/views/vmph/home.aspx

www.refaad.com

ISSN : 2707-7195(Online) 2707-7187(Print)

\title{
Effect of Spirulina Platensis on Some Serum Markers, Performance Metrics and Organ Weights, in Rats Fed with Hydrogenated Vegetable Oil and/or Cholesterol
}

\author{
Tanay Bilala, Ayşen Altinerb,* \\ aDepartment of Animal Nutrition and Nutritional Diseases, Faculty of Veterinary Medicine, Istanbul University-Cerrahpaşa, \\ Hadimköy, Büyükçekmece 34500, Istanbul, Turkey. tanbilal@istanbul.edu.tr \\ bepartment of Biochemistry, Faculty of Veterinary Medicine, Istanbul University-Cerrahpaşa, Hadimköy, Büyükçekmece \\ 34500, Istanbul, Turkey. altinera@istanbul.edu.tr \\ *Corresponding author: Ayşen Altiner (altinera@istanbul.edu.tr)
}

How to cite this article: Bilal \& Altiner. Effect of Spirulina Platensis on Some Serum Markers, Performance Metrics and Organ Weights, in Rats Fed with Hydrogenated Vegetable Oil and/or Cholesterol. Veterinary Medicine and Public Health Journal 1(2); 2020:60-69.

DOI: https://doi.org/10.31559/vmph2020.1.2.6

Received Date: 5/4/2020 Accepted Date: 27/4/2020

\begin{abstract}
The aim of this study was to investigate possible action of Spirulina platensis on serum adiponectin, phospholipid and some enzyme levels, performance metrics and organ weights, in rats induced by hydrogenated vegetable oil and/or cholesterol, which can open the way for using microalgae for therapeutic purposes. Sixty-four SpragueDawley rats were divided into eight equal groups and the groups consisted of one control and seven experimental groups. The control group was fed on a basal diet. In addition to the basal diet, the experimental groups were fed with: Group 1, 43\% hydrogenated vegetable oil; Group 2, 10\% cholesterol; Group 3, 43\% hydrogenated vegetable oil and 10\% cholesterol; Group 4, 3\% Spirulina platensis, Group 5, 43\% hydrogenated vegetable oil and 3\% Spirulina platensis, Group 6, 10\% cholesterol and 3\% Spirulina platensis, and Group 7, 43\% hydrogenated vegetable oil and 10\% cholesterol and 3\% Spirulina platensis. Blood samples were taken from all rats on Days 30 and 60. Feed intake was determined by measuring the amount of feed consumed and released daily. The feeding with cholesterol and/or Spirulina platensis significantly lowered the serum adiponectin levels. Dietary hydrogenated vegetable oil increased the serum phospholipids. Spirulina platensis supplementation significantly reduced serum aspartate aminotransferase activity on only Day 60. Hydrogenated vegetable oil supplementation to diet has increased the serum alanine aminotransferase activities. Gamma-glutamyl transpeptidase levels did not show a significant difference between the groups. The dose and treatment duration of Spirulina platensis in this study may not be sufficient. Higher doses of Spirulina platensis and its longer application period should be tested with different animal species.
\end{abstract}

Keywords: Adiponectin; Body weight; Feed intake; Organ weights; Spirulina platensis

\section{Introduction}

Spirulina is a free-floating microalgae in which the filaments have spiral properties. Spirulina was first classified in the plant kingdom due to its photosynthesis ability and the richness of plant pigments (Deng and Chow 2010). Later, because of its biochemical, genetic and physiological characteristics, it was placed on the bacteria kingdom based on a new understanding (Vonshak 1997). It has long been consumed as food by people in Central Africa and Mexico and is now widely used as nutritional supplements in Asia (Deng and Chow 2010) (Figure 1). Spirulina is a good source of the molecules such as $\gamma$-linolenic acid, minerals, phycocyanin, phenolic compounds, $\beta$ carotene and vitamins, which have antioxidant and anti-inflammatory properties (Gargouri et al. 2016a; Aladaileh et al. 2020) (Table 1). Phycocyanin may degrade free radicals such as peroxyl, alkoxyl and hydroxyl radicals (Deng and Chow 2010). Phycocyanin also reduces nitrite production, suppresses the expression of nitric oxide synthase 
and inhibits microsomal lipid peroxidation in the liver (Manconia et al. 2009). Administration of phycocyanin to a rat model of non-alcoholic steatohepatitis resulted in a significant reduction in the production of reactive oxygen species in leukocytes and in liver mitochondria (Pak et al. 2012).

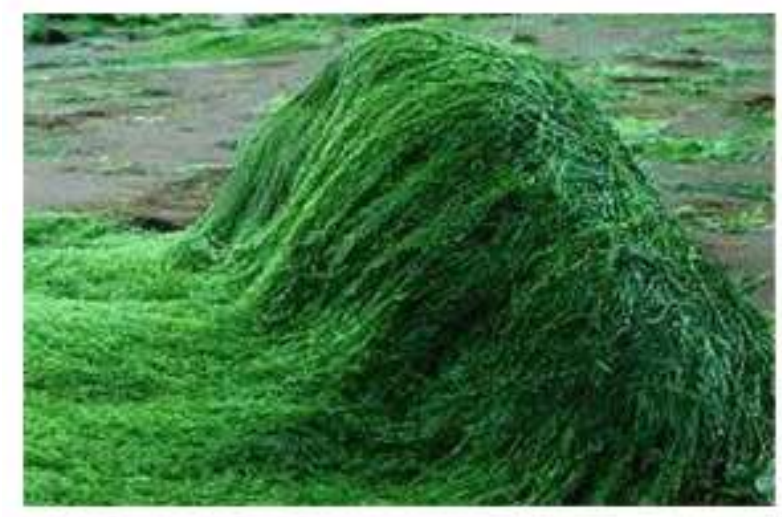

Fig (1): Spirulina platensis

(http://www.hashmidawakhana.co.in/spirulinaplatensis.html)

Table (1): General composition, essential fatty acids and pigments of Spirulina platensis (Vonshak 1997)

\begin{tabular}{|l|c|l|c|}
\hline $\begin{array}{l}\text { General } \\
\text { composition }\end{array}$ & $(\%)$ & $\begin{array}{l}\text { Essential fatty } \\
\text { acids }\end{array}$ & $(\mathrm{g} / \mathrm{kg})$ \\
\hline Moisture & $3-7$ & Linoleic acid & 8 \\
\hline Protein & $55-70$ & y-linoleic acid & 10 \\
\hline Fat (Lipids) & $6-8$ & $\underline{\text { Pigments }}$ & \\
\hline Carbohydrate & $15-25$ & Carotenoids & 3.7 \\
\hline Minerals (Ash) & $7-13$ & Chlorophyll & 10 \\
\hline Fiber & $8-10$ & Phycocyanin & 140 \\
\hline
\end{tabular}

Spirulina has many health benefits, including antibacterial, immunomodulatory, antiinflammatory, antioxidant, anticancer and antiviral activities as well as positive effects against obesity, malnutrition, heavy metal chemical toxicity, hyperlipidemia, diabetes and anemia (Liu et al. 2016). In recent years Spirulina has become increasingly popular as a potential source of pharmaceutical compound. It can be used to prevent or treat hepatic and kidney diseases (Abdel-Daim et al. 2013). It was also noted as a functional food in relation to its cholesterol regulatory properties (Hirata et al. 2000). High liver lipids supported by the high fat and cholesterol diet significantly decreased with Spirulina consumption (Kato et al. 1984). The results of some studies have shown that Spirulina as a dietary supplement has created a strategy to prevent health problems caused by free radicals (Belay 2002). Spirulina inhibited the increase in plasma phospholipids in fructoseinduced hyperlipidemic rats (Iwata et al. 1990). Moura et al. (2011) reported that Spirulina changed the non-alcoholic fatty liver disease and lipid profile in diabetic Wistar Albino rats. Today, interest in the use of algae for the treatment of diabetes is increasing (Hozayen et al. 2016).

Among the Spirulina species, Spirulina platensis, Spirulina maxima and Spirulina fusiformis have potential therapeutic value and are the most extensively investigated species because they have a high nutritional value (Karkos et al. 2011). The aim of this study was to investigate possible action of Spirulina platensis on serum adiponectin, phospholipid and some enzyme levels, performance metrics and organ weights, in rats induced by hydrogenated vegetable oil and/or cholesterol.

\section{Materials and methods Ethical issues}

This study was approved by Istanbul University-Cerrahpaşa Animal Care and Use Committee (Approval number: 2011/20). All animal experiments were carried out in accordance with the EU Directive 2010/63/EU for animal experiments.

\section{Animals}

Sixty-four 280-300 g male Sprague-Dawley rats were placed in polypropylene cages in a 12 hour dark/12 hour light environment. The animals were randomly divided into eight groups, consisting of a control and seven experimental groups.

\section{Feeding}

The trial period was 60 days. Food and water were given to the rats as ad libitum. 100\% pure Spirulina platensis in powder form was purchased from Alg BioTek (Istanbul, Turkey) and was administered to experimental animals at a dose of $3 \mathrm{~g} / 100 \mathrm{~g}$ diet (Yiğit et al. 2016). The control group was fed with the basal diet. In addition to the basal diet, the experimental groups were fed with: Group 1, 43\% hydrogenated vegetable oil; Group 2, 10\% cholesterol; Group 3, 43\% hydrogenated vegetable oil and 10\% cholesterol; Group 4, 3\% Spirulina platensis, Group 5, 43\% hydrogenated vegetable oil and 3\% Spirulina platensis, Group 6, 10\% cholesterol and 3\% Spirulina platensis, and Group 7, $43 \%$ hydrogenated vegetable oil and $10 \%$ cholesterol and 3\% Spirulina platensis. Compositon of diets is shown in Table 2.

\section{Laboratory methods}

Blood samples were collected from all rats by coccygeal venipuncture on Day 30 and by cardiac puncture on Day 60. The samples were centrifuged at $2.500 \mathrm{x} \mathrm{g}$ for 15 minutes, then the sera were transferred to $1.5 \mathrm{ml}$ microcentrifuge tubes and stored at $-80{ }^{\circ} \mathrm{C}$ until use. Serum phospholipid concentrations and serum alanine aminotransferase (ALT), aspartate aminotransferase (AST), alkaline phosphatase (ALP) and gamma-glutamyl transpeptidase (GGT) activities were determined by a biochemical analyzer (Cobas 8000 Modular System, Switzerland) using commercial kits (Ben Biochemical Enterprise Srl, Italy). Serum adiponectin concentrations were measured with an ELISA equipment ( $\mu$ Quant, Bio-Tek, , USA) using a commercial kit (SPI-BIO Bertin Pharma, France). All rats were weighed before the blood collection. Feed intake was calculated daily by removing the amount of feed left at the end of the day from the amount of feed given in the morning. 
Table (2): Dietary contents in rats fed with hydrogenated vegetable oil and/or cholesterol and/or Spirulina platensis (\%).

\begin{tabular}{|l|c|c|c|c|c|c|c|c|}
\hline Ingredients & Control & Group 1 & Group 2 & Group 3 & Group 4 & Group 5 & Group 6 & Group 7 \\
\hline Barley & & & & & & & & \\
\hline Wheat & 23 & 5 & 16 & - & 23 & 5 & 16 & - \\
\hline Rasmol & 42 & 7 & 36 & - & 42 & 7 & 36 & - \\
\hline Soybean meal & 15 & 15 & 15 & 15 & 12 & 12 & 12 & 12 \\
\hline Fish flour & 15 & 15 & 15 & 15 & 15 & 15 & 15 & 15 \\
\hline Vegetable oil & 2 & 12 & 5 & 14 & 2 & 12 & 5 & 14 \\
\hline Vitamin mineral premix & 2 & 2 & 2 & 2 & 2 & 2 & 2 & 2 \\
\hline Hydrogenated vegetable oil & 1 & 1 & 1 & 1 & 1 & 1 & 1 & 1 \\
\hline Cholesterol & - & 43 & - & 43 & - & 43 & - & 43 \\
\hline Spirulina platensis & - & - & 10 & 10 & - & - & 10 & 10 \\
\hline
\end{tabular}

Control=Basal diet; Group 1=Basal diet and 43\% hydrogenated vegetable oil; Group 2=Basal diet and 10\% cholesterol; Group 3=Basal diet and 43\% hydrogenated vegetable oil and 10\% cholesterol; Group 4=Basal diet and 3\% Spirulina platensis, Group 5=Basal diet and 43\% hydrogenated vegetable oil and 3\% Spirulina platensis; Group 6=Basal diet and $10 \%$ cholesterol and 3\% Spirulina platensis; Group 7=Basal diet and 43\% hydrogenated vegetable oil and 10\% cholesterol and $3 \%$ Spirulina platensis.

Feed conversion ratio (feed intake/body weight gain) was calculated for each group. At the end of the study, all rats were sacrificed and the liver, heart and kidneys were removed and wet organ weights were determined.

\section{Statistical analysis}

The results are presented as mean \pm the standard error of mean. Data were compared by using analysis of variance (ANOVA coupled with Tukey's multiple range test) at significance level of $\mathrm{p} \leq 0.05$ (Ergün and Aktaş 2009), between the groups in each blood sampling week for all blood markers and between the groups on Days 0-30 and 31-60 of the trial for performance metrics. All statistical analyses were performed using software package program (SPSS for windows, Standard version 10.0, 1999, SPSS Inc., USA).

\section{Results}

The concentrations of serum adiponectin and phospholipid, the activities of serum ALT, AST, ALP and GGT and the statistical comparisons of groups, on Day 30 in rats fed with basal diet and hydrogenated vegetable oil and/or cholesterol and/or Spirulina platensis, are indicated in Table 3.

Serum adiponectin concentrations were significantly lower in cholesterol group than in control, hydrogenated vegetable oil + cholesterol and hydrogenated vegetable oil + Spirulina platensis groups, on Day 30. The levels were significantly lower in hydrogenated vegetable oil + cholesterol + Spirulina platensis group than in hydrogenated vegetable oil + cholesterol group. Serum phospholipids were significantly higher in hydrogenated vegetable oil group than in cholesterol + Spirulina platensis and hydrogenated vegetable oil + cholesterol + Spirulina platensis groups, on Day 30. The hydrogenated vegetable oil in the diet increased serum phospholipids on Day 30, but the addition of cholesterol to the hydrogenated vegetable oil reduced the increase in phospholipids. Serum ALT and GGT activities were not significantly different between groups on Day 30. Serum AST activities were significantly lower in hydrogenated vegetable oil + cholesterol group than in hydrogenated vegetable oil, cholesterol and Spirulina platensis groups. Serum AST activities on Day 30, were higher in the Spirulina platensis group than in the hydrogenated vegetable oil + cholesterol + Spirulina platensis group, and in the cholesterol group than in the hydrogenated vegetable oil + cholesterol + Spirulina platensis group $(\mathrm{p} \leq 0.05)$. Serum ALP activities on Day 30, were significantly higher in the hydrogenated vegetable oil and hydrogenated vegetable oil + Spirulina platensis groups than in the other groups, and in the hydrogenated vegetable oil + cholesterol group than in the control, cholesterol, Spirulina platensis, cholesterol + Spirulina platensis and hydrogenated vegetable oil + cholesterol + Spirulina platensis groups (Table 3).

The concentrations of serum adiponectin and phospholipid, the activities of serum ALT, AST, ALP and GGT and the statistical comparisons of groups, on Day 60 in rats fed with basal diet and hydrogenated vegetable oil and/or cholesterol and/or Spirulina platensis, are indicated in Table 4. Serum adiponectin was significantly lower in cholesterol, Spirulina platensis and cholesterol + Spirulina platensis groups than in control and hydrogenated vegetable oil + cholesterol groups, on Day 60. Serum phospholipids were significantly higher in hydrogenated vegetable oil group than in other all groups, on Day 60. Serum ALT activity was higher in hydrogenated vegetable oil + cholesterol + Spirulina platensis group than in control, cholesterol and hydrogenated vegetable oil + cholesterol groups $(p \leq 0.05)$. Serum AST activity was significantly lower in hydrogenated vegetable oil + cholesterol + Spirulina platensis group than in hydrogenated vegetable oil, cholesterol, hydrogenated vegetable oil + cholesterol and Spirulina platensis groups, on Day 60. 
Table (3): Some serum markers in rats fed with hydrogenated vegetable oil and/or cholesterol and/or Spirulina platensis, on Day 30

\begin{tabular}{|c|c|c|c|c|c|c|c|c|}
\hline Markers & Control & Group 1 & Group 2 & Group 3 & Group 4 & Group 5 & Group 6 & Group 7 \\
\hline $\begin{array}{l}\text { Adiponectin, } \\
\mathrm{ng} / \mathrm{ml}\end{array}$ & $2.51 \pm 0.11^{\mathrm{ab}}$ & $\begin{array}{l}2.26 \pm 0.12^{\mathrm{b}} \\
\mathrm{c}\end{array}$ & $2.00 \pm 0.05^{c}$ & $2.75 \pm 0.17^{a}$ & $\begin{array}{l}2.25 \pm 0.16^{b} \\
c\end{array}$ & $\begin{array}{l}2.50 \pm 0.13^{a} \\
b\end{array}$ & $1.97 \pm 0.06^{c}$ & $2.06 \pm 0.05^{c}$ \\
\hline $\begin{array}{l}\text { Phospholipid, } \\
\text { mg/dl }\end{array}$ & $85.9 \pm 3.4^{\mathrm{ab}}$ & $99.7 \pm 4.2^{\mathrm{a}}$ & $88.0 \pm 6.3^{\mathrm{ab}}$ & $87.1 \pm 5.5^{\mathrm{ab}}$ & $85.2 \pm 3.6^{\mathrm{ab}}$ & $90.5 \pm 4.4^{\mathrm{ab}}$ & $72.2 \pm 3.6^{b}$ & $74.5 \pm 1.8^{\mathrm{b}}$ \\
\hline ALT, IU/l & $38.7 \pm 5.2$ & $42.0 \pm 2.5$ & $42.8 \pm 1.8$ & $40.9 \pm 5.3$ & $42.6 \pm 3.0$ & $36.9 \pm 3.1$ & $34.6 \pm 3.3$ & $32.4 \pm 3.6$ \\
\hline AST, IU/l & $76.0 \pm 4.5^{\mathrm{abcd}}$ & $77.7 \pm 4.0^{\mathrm{abc}}$ & $91.9 \pm 3.8^{a}$ & $60.6 \pm 4.2^{\mathrm{d}}$ & $81.6 \pm 1.5^{\mathrm{ab}}$ & $\begin{array}{l}70.7 \pm 3.5^{b c} \\
d\end{array}$ & $\begin{array}{l}75.0 \pm 5.5^{b c} \\
d\end{array}$ & $62.8 \pm 2.4^{\mathrm{cd}}$ \\
\hline ALP, IU/l & $245 \pm 21^{c}$ & $667 \pm 28 \mathrm{a}$ & $247 \pm 27 \mathrm{c}$ & $518 \pm 41^{b}$ & $196 \pm 26^{c}$ & $653 \pm 54^{a}$ & $164 \pm 9.4 \mathrm{c}$ & $279 \pm 15^{c}$ \\
\hline GGT, IU/l & $0.81 \pm 0.24$ & $0.79 \pm 0.33$ & $1.12 \pm 0.31$ & $1.31 \pm 0.40$ & $0.69 \pm 0.21$ & $0.92 \pm 0.30$ & $1.41 \pm 0.34$ & $1.79 \pm 0.36$ \\
\hline
\end{tabular}

$\mathrm{n}=8$; Mean \pm Standard error; $\mathrm{a}, \mathrm{b}, \mathrm{c}, \mathrm{d}=$ Means within a row with different superscripts are significantly different ( $\mathrm{p} \leq 0.05$ ); ALT=Alanine aminotransferase; AST=Aspartate aminotransferase; ALP=Alkaline phosphatase; GGT $=$ Gammaglutamyltransferase; Control=Basal diet; Group 1=Basal diet and 43\% hydrogenated vegetable oil; Group 2=Basal diet and 10\% cholesterol; Group 3=Basal diet and 43\% hydrogenated vegetable oil and 10\% cholesterol; Group 4=Basal diet and 3\% Spirulina platensis; Group 5=Basal diet and 43\% hydrogenated vegetable oil and 3\% Spirulina platensis; Group 6=Basal diet and 10\% cholesterol and 3\% Spirulina platensis; Group 7=Basal diet and 43\% hydrogenated vegetable oil and 10\% cholesterol and 3\% Spirulina platensis.

Serum ALP activities were significantly higher in hydrogenated vegetable oil, hydrogenated vegetable oil + cholesterol and hydrogenated vegetable oil + Spirulina platensis groups than in control, cholesterol, Spirulina platensis and cholesterol + Spirulina platensis groups. Serum ALP activity was higher in hydrogenated vegetable oil + cholesterol + Spirulina platensis group than in cholesterol + Spirulina platensis group $(\mathrm{p} \leq 0.05)$. Serum GGT activities were not significantly different between groups on Day 60 (Table 4).

Table (4): Some serum markers in rats fed with hydrogenated vegetable oil and/or cholesterol and/or Spirulina platensis, on Day 60

\begin{tabular}{|l|l|l|l|l|l|l|l|l|}
\hline Markers & Control & Group 1 & Group 2 & Group 3 & Group 4 & Group 5 & Group 6 & Group 7 \\
\hline $\begin{array}{l}\text { Adiponectin, } \\
\text { ng/ml }\end{array}$ & $2.82 \pm 0.04^{\mathrm{a}}$ & $2.66 \pm 0.11^{\mathrm{abc}}$ & $\begin{array}{l}2.42 \pm 0.09^{\mathrm{c}} \\
\mathrm{d}\end{array}$ & $2.84 \pm 0.08^{\mathrm{a}}$ & $2.35 \pm 0.04^{\mathrm{d}}$ & $\begin{array}{l}2.76 \pm 0.06^{\mathrm{a}} \\
\mathrm{b}\end{array}$ & $2.53 \pm 0.17^{\mathrm{bcd}}$ & $\begin{array}{l}2.77 \pm 0.08^{\mathrm{a}} \\
\mathrm{b}\end{array}$ \\
\hline $\begin{array}{l}\text { Phospholipid, } \\
\mathrm{mg} / \mathrm{dl}\end{array}$ & $84.8 \pm 2.9^{\mathrm{b}}$ & $110 \pm 7.1^{\mathrm{a}}$ & $82.2 \pm 2.9^{\mathrm{b}}$ & $78.1 \pm 3.9^{\mathrm{b}}$ & $82.1 \pm 3.1^{\mathrm{b}}$ & $92.1 \pm 4.1^{\mathrm{b}}$ & $92.5 \pm 4.2^{\mathrm{b}}$ & $75.9 \pm 3.6^{\mathrm{b}}$ \\
\hline ALT, IU/l & $41.0 \pm 3.0^{\mathrm{b}}$ & $52.4 \pm 5.3^{\mathrm{ab}}$ & $44.9 \pm 3.4^{\mathrm{b}}$ & $44.8 \pm 1.8^{\mathrm{b}}$ & $53.5 \pm 2.7^{\mathrm{ab}}$ & $52.6 \pm 4.9^{\mathrm{ab}}$ & $50.4 \pm 5.7^{\mathrm{ab}}$ & $70.2 \pm 7.8^{\mathrm{a}}$ \\
\hline AST, IU/l & $86.9 \pm 5.6^{\mathrm{ab}}$ & $99.9 \pm 3.5^{\mathrm{a}}$ & $95.6 \pm 5.8^{\mathrm{a}}$ & $88.0 \pm 6.2^{\mathrm{a}}$ & $93.3 \pm 6.0^{\mathrm{a}}$ & $85.0 \pm 4.3^{\mathrm{ab}}$ & $86.7 \pm 3.8^{\mathrm{ab}}$ & $64.7 \pm 7.1^{\mathrm{b}}$ \\
\hline ALP, IU/l & $360 \pm 49^{\mathrm{bcd}}$ & $617 \pm 68^{\mathrm{a}}$ & $264 \pm 30^{\mathrm{cd}}$ & $537 \pm 59^{\mathrm{a}}$ & $383 \pm 31^{\mathrm{bcd}}$ & $531 \pm 58^{\mathrm{a}}$ & $204 \pm 29^{\mathrm{d}}$ & $473 \pm 66^{\mathrm{abc}}$ \\
\hline GGT, IU/l & $0.98 \pm 0.29$ & $1.59 \pm 0.34$ & $1.35 \pm 0.23$ & $1.42 \pm 0.28$ & $1.72 \pm 0.23$ & $1.51 \pm 0.37$ & $1.87 \pm 0.22$ & $2.13 \pm 0.33$ \\
\hline
\end{tabular}

$\mathrm{n}=8$; Mean \pm Standard error; $\mathrm{a}, \mathrm{b}, \mathrm{c}, \mathrm{d}=$ Means within a row with different superscripts are significantly different $(\mathrm{p} \leq 0.05)$ ALT=Alanine aminotransferase; $\quad$ AST $=$ Aspartate aminotransferase; ALP=Alkaline phosphatase; GGT $=$ Gammaglutamyltransferase; Control=Basal diet; Group 1=Basal diet and 43\% hydrogenated vegetable oil; Group 2=Basal diet and 10\% cholesterol; Group 3=Basal diet and 43\% hydrogenated vegetable oil and 10\% cholesterol; Group 4=Basal diet and 3\% Spirulina platensis; Group 5=Basal diet and 43\% hydrogenated vegetable oil and 3\% Spirulina platensis; Group 6=Basal diet and 10\% cholesterol and 3\% Spirulina platensis; Group 7=Basal diet and 43\% hydrogenated vegetable oil and $10 \%$ cholesterol and $3 \%$ Spirulina platensis.

The organ weights and the statistical comparisons of groups in the rats fed with basal diet and hydrogenated vegetable oil and/or cholesterol and/or Spirulina platensis are indicated in Table 5.

Liver weights were higher in cholesterol, hydrogenated vegetable oil + cholesterol and hydrogenated vegetable oil + cholesterol + Spirulina platensis groups than in hydrogenated vegetable oil and hydrogenated vegetable oil + Spirulina platensis groups $(\mathrm{p} \leq 0.05)$. Liver weight in the control group was not significantly different than in the other all groups. There were no significant differences between groups for heart weights. Kidney weights were significantly higher in control, cholesterol and cholesterol + Spirulina platensis groups than in hydrogenated vegetable oil + Spirulina platensis group (Table 5).

The performance metrics of groups in rats fed with basal diet and hydrogenated vegetable oil and/or cholesterol and/or Spirulina platensis are indicated in Table 6. There were no significant differences between groups in terms of body weights, feed intake and feed conversion ratios (Table 6).

\section{Discussion}

Adiponectin regulates the metabolism of glucose, increases the oxidation of fat and the transport of glucose in muscles, inhibits the glyconeogenesis in the liver and activates the peroxisome proliferator-activated receptor- $\alpha$, which leads to a decrease in the triglyceride content in the liver and skeletal muscles (Hozayen et al. 2016). The serum level of adiponectin is consistent with insulin sensitivity and low levels are related to insulin resistance (Statnick et al. 2000). Adiponectin is known to inhibit expression of tumor necrosis factor- $\alpha$ which is a pro-inflammatory cytokine in some tissues (Bastard et al. 2000). 
Lee et al. (2008) showed a significant increase in the plasma concentration of adiponectin after addition of Spirulina platensis. The plasma level of adiponectin in the group with Spirulina platensis tended to increase (from $5.52 \mu \mathrm{g} / \mathrm{ml}$ to $6.62 \mu \mathrm{g} / \mathrm{ml}$, $\mathrm{p}<0.1$. The authors stated that the increase in concentration of adiponectin due to decreased oxidative stress was involved in the prevention of diabetes mellitus complication. Hozayen et al. (2016) found that oral administration of Spirulina versicolor to diabetic rats increased the insulin sensitivity and the serum concentration of adiponectin and weakened the oxidative stress and inflammation. They also reported that the beneficial effects of Spirulina versicolor may in part be explained by the ability to increase serum adiponectin levels in fructose-induced diabetic rats. Moreover, they thought that inhibition of tumor necrosis factor- $\alpha$ release after administration of Spirulina versicolor extract may be a result of an increase in serum adiponectin levels.

Table (5): Weights of some organs in rats fed with hydrogenated vegetable oil and/or cholesterol and/or Spirulina platensis (g)

\begin{tabular}{|l|l|l|l|l|l|l|l|l|}
\hline Organs & Control & Group 1 & Group 2 & Group 3 & Group 4 & Group 5 & Group 6 & Group 7 \\
\hline Liver & $10.9 \pm 0.37^{\mathrm{abc}}$ & $9.2 \pm 0.22^{\mathrm{c}}$ & $11.3 \pm 0.33^{\mathrm{ab}}$ & $12.4 \pm 0.71^{\mathrm{a}}$ & $10.3 \pm 0.34^{\mathrm{bc}}$ & $9.0 \pm 0.39^{\mathrm{c}}$ & $10.7 \pm 0.69^{\mathrm{abc}}$ & $11.6 \pm 0.26^{\mathrm{ab}}$ \\
\hline Heart & $1.23 \pm 0.08$ & $1.22 \pm 0.03$ & $1.29 \pm 0.09$ & $1.24 \pm 0.03$ & $1.14 \pm 0.03$ & $1.16 \pm 0.03$ & $1.11 \pm 0.07$ & $1.20 \pm 0.05$ \\
\hline Kidney & $2.65 \pm 0.13^{\mathrm{a}}$ & $2.43 \pm 0.10^{\mathrm{ab}}$ & $2.62 \pm 0.08^{\mathrm{a}}$ & $2.29 \pm 0.04^{\mathrm{ab}}$ & $2.33 \pm 0.06^{\mathrm{ab}}$ & $2.12 \pm 0.08^{\mathrm{b}}$ & $2.52 \pm 0.14^{\mathrm{a}}$ & $2.35 \pm 0.05^{\mathrm{ab}}$ \\
\hline
\end{tabular}

$\mathrm{n}=8$; Mean \pm Standard error; a,b,c $=$ Means within a row with different superscripts are significantly different (p $\leq 0.05$ ); Control=Basal diet; Group 1=Basal diet and 43\% hydrogenated vegetable oil; Group 2=Basal diet and 10\% cholesterol; Group $3=$ Basal diet and 43\% hydrogenated vegetable oil and 10\% cholesterol; Group 4=Basal diet and 3\% Spirulina platensis; Group $5=$ Basal diet and 43\% hydrogenated vegetable oil and 3\% Spirulina platensis; Group 6=Basal diet and 10\% cholesterol and $3 \%$ Spirulina platensis; Group 7=Basal diet and 43\% hydrogenated vegetable oil and 10\% cholesterol and 3\% Spirulina platensis.

Fujimoto et al. (2012) found that adiponectin insignificantly change in the Spirulina group. Martinez-Sesmero et al. (2009) reported low levels of adiponectin in obesity. Plasma adiponectin level was significantly lower in the Spirulina and glucomannan group $(6.81 \mu \mathrm{g} / \mathrm{ml})$ than the control group $(8.63 \mu \mathrm{g} / \mathrm{ml})$ (Vázquez-Velasco et al. 2015). In the present study, serum adiponectin concentrations were significantly lower in hydrogenated vegetable oil + cholesterol + Spirulina platensis group than in hydrogenated vegetable oil + cholesterol group on Day 30 (Table 3). Serum adiponectin was significantly lower in cholesterol, Spirulina platensis and cholesterol + Spirulina platensis groups than in control and hydrogenated vegetable oil + cholesterol groups, on Day 60 (Table 4). These findings are in agreement with the findings of Vázquez-Velasco et al. (2015). Such a role of Spirulina can be attributed to the rich nutrient content resulting from the presence of minerals (especially copper, manganese, iron, calcium and zinc), bioactive pigments (phycocyanin, chlorophyll, $\beta$-carotene), vitamins, essential amino acids and proteins (Gargouri et al. 2016b).

Experiments with different animals have shown that addition of Spirulina to the diet may lead to a reduction in plasma (Hosoyamada et al. 1991) and hepatic (González de Rivera et al. 1993) phospholipids. In a study with mice (Deng and Chow 2010 ), the addition of $16 \%$ Spirulina to a diet containing high levels of fat and cholesterol resulted in a significant reduction in phospholipids. Similarly, in a study of Iwata et al. (1990), elevation of phospholipids was significantly reduced by addition of Spirulina. In our study as similar to findings of Hosoyamada et al. (1991), Deng and Chow (2010) and Iwata et al. (1990), serum phospholipids on Day 30 were significantly higher in the hydrogenated vegetable oil group than in the cholesterol +
Spirulina platensis and hydrogenated vegetable oil + cholesterol + Spirulina platensis groups (Table 3). Serum phospholipids were significantly higher in hydrogenated vegetable oil group than in other all groups on Day 60 (Table 4). Gargouri et al. (2016b) reported that addition of Spirulina to rats' diet reduced peroxidation of lipids and showed liver protective effect. Gad et al. (2011) found that Spirulina protected liver against oxidative stress by scavenging free radicals. Upasani and Balaraman (2003) reported that the protective and antioxidant effects of Spirulina are caused by the antioxidants such as minerals, vitamins, $\beta$-carotene, phycocyanins and proteins.

Serum AST and ALT activities are common indicators of hepatotoxicity (Yang et al. 2009). Increased activity of serum liver enzymes (AST, ALT) may be due to the deterioration of the functional integrity of the liver cell membranes and the infiltration of these enzymes outside the cell (Ibrahim et al. 2011). In a study, no significant difference was found between the control group and the Spirulina group in terms of AST (41.7 IU/l vs. $52.9 \mathrm{IU} / \mathrm{l})$ and ALT (18.9 IU/l vs. $15.2 \mathrm{IU} / \mathrm{l})$ activities, respectively (Fujimoto et al. 2012). Similarly, no significant difference was observed between control and Spirulina groups in terms of serum AST and ALT activities in fatty liver disease caused by pioglitazone use (Yang et al. 2003). However, Ding et al. (2004) reported that Spirulina was given to liver-damaged mice for 45 days, and caused a decrease in serum ALT activity. Similarly, addition of Spirulina to the diet of the mothers who underwent lead application significantly reduced serum AST and ALT activities in their offspring $(\mathrm{p}<0.01)$ (Gargouri et al. 2016b). Sharma et al. (2007) reported that Spirulina added to the diet (daily $0.8 \mathrm{~g} / \mathrm{kg}$ ) reduced serum ALT and AST activities in mice administered mercury chloride. Gargouri et al. (2016a) reported 
Table (6): Some performance metrics in rats fed with hydrogenated vegetable oil and/or cholesterol and/or Spirulina platensis

\begin{tabular}{|c|c|c|c|c|c|c|c|c|}
\hline Metrics & Control & Group 1 & Group 2 & Group 3 & Group 4 & Group 5 & Group 6 & Group 7 \\
\hline \multicolumn{9}{|c|}{ Body weight (g) } \\
\hline Day 0 & $306 \pm 13.1$ & $305 \pm 10.7$ & $305 \pm 13.3$ & $306 \pm 11.0$ & $305 \pm 6.3$ & $306 \pm 6.5$ & $305 \pm 14.5$ & $305 \pm 13.3$ \\
\hline Day 30 & $325 \pm 8.8$ & $315 \pm 10.2$ & $327 \pm 9.1$ & $322 \pm 10.7$ & $315 \pm 4.8$ & $314 \pm 7.9$ & $315 \pm 14.6$ & $321 \pm 11.0$ \\
\hline \multicolumn{9}{|c|}{ Feed intake (g) } \\
\hline Days 0-30 & 22.3 & 14.6 & 23.5 & 17.5 & 20.2 & 13.6 & 22.4 & 15.0 \\
\hline Days 31-60 & 22.0 & 14.8 & 23.8 & 17.3 & 20.4 & 14.6 & 24.0 & 17.0 \\
\hline \multicolumn{9}{|c|}{ Feed conversion ratio } \\
\hline Days $0-30$ & 1.15 & 1.52 & 1.08 & 1.06 & 2.19 & 1.68 & 2.24 & 0.93 \\
\hline Days 31-60 & 1.13 & 1.67 & 1.25 & 1.10 & 2.52 & 1.08 & 2.13 & 0.75 \\
\hline
\end{tabular}

$\mathrm{n}=8$; Mean \pm Standard error; Control=Basal diet; Group 1=Basal diet and 43\% hydrogenated vegetable oil; Group 2=Basal diet and 10\% cholesterol; Group 3=Basal diet and 43\% hydrogenated vegetable oil and 10\% cholesterol; Group 4=Basal diet and 3\% Spirulina platensis; Group 5=Basal diet and 43\% hydrogenated vegetable oil and 3\% Spirulina platensis; Group 6=Basal diet and 10\% cholesterol and 3\% Spirulina platensis; Group 7=Basal diet and 43\% hydrogenated vegetable oil and 10\% cholesterol and 3\% Spirulina platensis.

that serum AST and ALT activities were significantly elevated for 21 days in alloxane-induced diabetic rats, but these activities were significantly reduced after addition of Spirulina to the rats' diet. The addition of Spirulina versicolor to the diabetic rats' diet significantly reduced serum AST activity $(\mathrm{p}<0.05)$ (Hozayen et al. 2016). Torres-Durán et al. (2006) observed that the addition of 5\% Spirulina to the diet of rats induced by carbon tetrachloride significantly reduced serum AST activities.

In the study, serum ALT activities did not show any significant difference between the groups on Day 30 (Table 3). Serum ALT activity in hydrogenated vegetable oil + cholesterol + Spirulina platensis group was higher at 60 days than control, cholesterol and hydrogenated vegetable oil + cholesterol groups $(\mathrm{p} \leq 0.05)$ (Table 4). Serum AST activities were significantly lower in hydrogenated vegetable oil + cholesterol group than in hydrogenated vegetable oil, cholesterol and Spirulina platensis groups on Day 30. Levels were higher in cholesterol and Spirulina platensis groups than in hydrogenated vegetable oil + cholesterol + Spirulina platensis group on Day $30(\mathrm{p} \leq 0.05)$ (Table 3 ). Serum AST activity was significantly lower in hydrogenated vegetable oil + cholesterol + Spirulina platensis group than in hydrogenated vegetable oil, cholesterol, hydrogenated vegetable oil + cholesterol and Spirulina platensis groups, on Day 60 (Table 4). Spirulina platensis supplementation significantly reduced serum AST activity on only Day 60 (Group 3 vs. Group 7). However, it increased serum ALT activity on Day 60 (Group 3 vs. Group 7), and serum AST activity on Day 30 (Group 3 vs. Group 4). This was not an expected situation. This may be due to the short-term addition of Spirulina to the diet (only 60 days). The finding that Spirulina platensis reduced serum AST activity on Day 60 is consistent with the findings of Sharma et al. (2007), Gargouri et al. (2016a,b), Hozayen et al. (2016), and Torres-Durán et al. (2006). This may indicate that Spirulina plays a protective role against liver dysfunction and provides tissue regeneration (Gargouri et al. 2016b). Gargouri et al. (2016b) reported that the liver protective effect of Spirulina may be related to the preservation of the structural integrity of the cell, such as the prevention of oxidative damage of DNA through the stabilization of the plasma membrane and hence the repair of hepatic tissue damage. Bhat and Madyastha (2001) stated that the phycocyanin, a blue pigment in the structure of Spirulina, has a special protective role against DNA damage.

Kumar et al. (2009) found that Spirulina (0.4 $\mathrm{g} / \mathrm{kg} /$ day) added to the diet for 45 days resulted in a decrease in serum activities of ALP in collageninduced rats. Gargouri et al. (2016a) reported that serum ALP activity increased significantly in diabetic rats treated with alloxane for 21 days, but significantly decreased after addition of Spirulina to the diet. Abdel-Daim et al. (2018) noted that serum concentrations of ALP were significantly higher $(p<0.05)$ in the diazinon-intoxicated group, compared to normal controls and the administration of Spirulina platensis significantly ameliorated these alterations. In our study, serum ALP activities on Day 30 were significantly higher in hydrogenated vegetable oil + cholesterol group than in control, cholesterol, Spirulina platensis, cholesterol + Spirulina platensis, and hydrogenated vegetable oil + cholesterol + Spirulina platensis groups. Also, they were significantly higher in hydrogenated vegetable oil and hydrogenated vegetable oil + Spirulina platensis groups than in other groups (Table 3). Serum ALP activities were significantly higher in hydrogenated vegetable oil, hydrogenated vegetable oil + cholesterol and hydrogenated vegetable oil + Spirulina platensis groups than in control, cholesterol, Spirulina platensis and cholesterol + Spirulina platensis groups on Day 60 . Also, it was higher in hydrogenated vegetable oil + cholesterol + Spirulina platensis group than in cholesterol + Spirulina platensis group $(\mathrm{p} \leq 0.05)$ (Table 4). As expected, the addition of hydrogenated vegetable oil to the diet increased serum ALP activities, and Spirulina platensis supplementation reduced them. This is similar to findings of Kumar et al. (2009), Gargouri et al. (2016a) and Abdel-Daim et al. (2018). Free radicals are produced as a result of impaired liver function (Gargouri et al. 2016a). Spirulina is useful in improving liver function in rats with fatty liver disease due to their high nutritional 
value and strong antioxidant content (Hosseini et al. 2013).

The liver is the largest internal organ in the body and plays a crucial role in the detoxification of toxic substances. The liver has a regulatory effect on many of the important metabolic functions and is responsible for maintaining body homeostasis (Mayuren et al. 2010). Fujimoto et al. (2012) reported that Spirulina reduced oxidative stress and lipid accumulation in the liver, as well as reducing the infiltration of macrophages into the visceral fat, thereby preventing the progression of liver fattening. They (Fujimoto et al. 2012) also stated that the group added Spirulina to the diet had significantly less liver/body weight ratio than the monosodium glutamate added group. The addition of Spirulina to the rats' diet 2 weeks before the onset of fatty liver reduced the lipid accumulation in the liver by $40 \%$; the addition of $5 \%$ Spirulina to the diet 1 week after alloxan administration for 4 weeks prevented the formation of fatty liver (Deng and Chow 2010). The addition of phycocyanine and Spirulina to the diet of rats with non-alcoholic fatty liver significantly decreased the liver fibrosis and the increase of liver enzymes in plasma (Pak et al. 2012). According to Fujimoto et al. (2012), Spirulina lowered body weight more than pioglitazone $(\mathrm{p}<0.05)$, and this was probably due to a decrease in liver weight. Sadek et al. (2017) reported that Spirulina platensis improves damaged hepatocytes.

Vidé et al. (2015) reported that, although the number of polymorphonuclear cells decreased, Spirulina could not protect liver from being fattened in a high-fat diet-fed group. Gargouri et al. (2016a) found that liver weight was significantly lower in alloxane-treated rats than in the untreated group and Spirulina added to the diet did not affect liver weight. In the present study, liver weights were higher in cholesterol, hydrogenated vegetable oil + cholesterol and hydrogenated vegetable oil + cholesterol + Spirulina platensis groups than in hydrogenated vegetable oil and hydrogenated vegetable oil + Spirulina platensis groups $(\mathrm{p} \leq 0.05)$. Level in the control group was not significantly different than in the other all groups (Table 5). Cholesterol supplementation increased liver weights. Spirulina platensis supplementation did not change the liver weights. This finding is similar to the findings of Vidé et al. (2015) and Gargouri et al. (2016a). The dose of Spirulina platensis may have been insufficient to reduce liver weight.

Hydroalcoholic extract of Spirulina platensis significantly increased body weights of rats with dextran sulfate sodium-induced ulcerative colitis (Morsy et al. 2019). Rats that received Spirulina achieved a significant increase in body weight compared to controls (Elshazly et al. 2015). However, in one study, mice receiving Spirulina supplementation had significantly lower body weight than mice receiving pioglitazone or monosodium glutamate (Fujimoto et al. 2012). Zeinalian et al. (2017) found that the decrease in body mass index of Spirulina platensis group was significantly higher than the placebo group. Gupta et al. (2010) reported that dexamethasone increased body weight in rats and this reversed 7 days after Spirulina administration. Addition of glucomannan and Spirulina-surimi to a highly saturated hyperenergetic diet reduced the weight gain (Vázquez-Velasco et al. 2015). Mice receiving 5\% Spirulina supplementation for 4 weeks had a significant reduction in body weights compared to the control group 1 week after addition of alloxane to the diet (Deng and Chow 2010). Individuals with ischemic heart disease receiving $2 \mathrm{~g}$ or $4 \mathrm{~g}$ of Spirulina per day for 3 months had significant reductions in body weight (Ramamoorthy and Premakumari 1996). In one study (Miczke et al. 2016), 2 g of Spirulina was given to obesity patients per day for 3 months, reducing body weight and body mass index.

In a study performed, a significant increase $(p<0.05)$ was observed in the final weight (Day 60) compared to baseline (Day 0), but no significant difference was found between animals in all groups (Bertolin et al. 2009). Similarly, Araújo et al. (2003) found that Spirulina added to the diet did not alter the body weight of the animals. Furthermore, Moura et al. (2012) reported no difference in body weight between groups with and without addition of Spirulina. The addition of Spirulina to the diet did not affect body weight without showing any toxicity in rats (Salazar et al. 1996). In the study of Iwata et al. (1990), the body weights of all groups with Spirulina added were higher than group consuming a high percentage of fat but the differences between groups were not significant. In the present study, no significant difference was detected between groups in terms of body weight (Table 6). This finding is consistent with the findings of Bertolin et al. (2009), Araújo et al. (2003), Moura et al. (2012), Salazar et al. (1996), and Iwata et al. (1990).

In one study, the administration of different doses of Spirulina to mice for 12 weeks did not affect feed intake (Deng and Chow 2010). Araújo et al. (2003) and Bertolin et al. (2009) found that a dietary supplement with Spirulina did not alter the feed intake of animals. Moura et al. (2012) found no significant difference between the Spirulina group and the control group in terms of feed intake. Similarly, Vázquez-Velasco et al. (2015) reported that the addition of Spirulina-surimis and glucomannan to a highly saturated hypereneric diet did not alter feed consumption (control $34.18 \mathrm{~g} /$ day vs. glucomannan + Spirulina $34.22 \mathrm{~g} /$ day). There were no significant differences between the groups in terms of feed intake in our study (Table 6). This is consistent with Deng and Chow (2010), Araújo et al. (2003), Bertolin et al. (2009), Moura et al. (2012), and Vázquez-Velasco et al. (2015).

\section{Conclusions}

The feeding with cholesterol and/or Spirulina platensis significantly lowered the serum adiponectin levels. Dietary hydrogenated vegetable 
oil increased the serum phospholipids. Spirulina platensis supplementation significantly reduced serum AST activity on Day 60. Hydrogenated vegetable oil supplementation to diet has increased the serum ALP activities. In conclusion, all levels were within normal ranges. The dose and treatment duration of Spirulina platensis in this study may not be sufficient. Higher doses of Spirulina platensis and its longer application period should be tested with different animal species.

\section{Conflict of Interest}

Authors declare that there are no known conflicts of interest associated with this publication and there has been no significant financial support for this work that could have influenced its outcome.

\section{Acknowledgment}

The study was financially supported by the Scientific Research Project Committee of Istanbul University-Cerrahpaşa. (Project numbers: NAP2015-15961, BEK-56323).

\section{References}

[1] Abdel-Daim. MM., Abuzead. SM. \& Halawa. SM., Protective role of Spirulina platensis against acute deltamethrin-induced toxicity in rats, PLoS One 8(9)(2013), e72991, https://doi.org/10.1371/journal.pone.0072991

[2] Abdel-Daim. MM., Abushouk. AI., Alkhalf. MI., Toraih. EA., Fawzy. MS., Ijaz. H., Aleya. L. \& Bungau. SG., Antagonistic effects of Spirulina platensis on diazinon-induced hematobiochemical alterations and oxidative stress in rats, Environ Sci Pollut Res, 25(2018), 2746327470, https://doi.org/10.1007/s11356-018-2761-0

[3] Aladaileh. SH., Khafaga. AF., Abd El-Hack. ME., Al-Gabri. NA., Abukhalil. MH., Alfwuaires. MA., Bin-Jumah. M., Alkahtani. S., Abdel-Daim. MM., Aleya. L. \& Abdelnour. S., Spirulina platensis ameliorates the sub chronic toxicities of lead in rabbits via anti-oxidative, anti- inflammatory, and immune stimulatory properties, Sci Total Environ, 701(2020), 134879, https://doi.org/10.1016/j.scitotenv.2019.134879

[4] Araújo. KGL., Facchinetti. AD. \& Santos. CP., Influence of consumption of Spirulina (Arthrospira sp.) biomasses on body weight and food intake in rats, Food Sci Technol, 23(1)(2003), 6-9, https://doi.org/10.1590/S010120612003000100003

[5] Bastard. JP., Piéroni. L. \& Hainque. B., Relationship between plasma plasminogen activator inhibitor 1 and insulin resistance, Diabetes Metab Res Rev, 16(3)(2000), 192-201, https://doi.org/10.1002/1520-

7560(200005/06)16:3<192::aid-dmrr114>3.0.co;2-g

[6] Belay. A., The potential application of Spirulina (Arthrospira) as a nutritional and therapeutic supplement in health management. JANA, 5(2)(2002), 27-48.
[7] Bertolin. TE., Pilatti. D., Giacomini. ACVV., Bavaresco. CS., Colla. LM. \& Costa. JAV. Effect of microalga Spirulina platensis (Arthrospira platensis) on hippocampus lipoperoxidation and lipid profile in rats with induced hypercholesterolemia, Braz Arch Biol Technol, 52(5)(2009), 1253-1259, https://doi.org/10.1590/s1516-89132009000500024

[8] Bhat. VB. \& Madyastha. KM. Scavenging of peroxynitrite by phycocyanin and phycocyanobilin from Spirulina platensis: protection against oxidative damage to DNA. Biochem Biophys Res Commun, 285(2)(2001) 262-266, https://doi.org/10.1006/bbrc.2001.5195

[9] Deng. R. \& Chow. TJ., Hypolipidemic, antioxidant, and antiinflammatory activities of microalgae Spirulina. Cardiovasc Ther, 28(4)(2010), e33-45, https://doi.org/ 10.1111/j.1755-5922.2010.00200.x

[10] Ding. J., Jin. A., Shi. L., Tianyao. H. \& Cheng. H. Effect of Spirulina on antioxidation ability of liver during $\mathrm{CCl}_{4}$ induced chronic liver injury in mice, J Lake Sci, 16(4)(2004), 343-348, https://doi.org/10.18307/2004.0409

[11] Elshazly. MO., Abd El-Rahman. SS., Morgan. AM. \& Ali. ME. The remedial efficacy of Spirulina platensis versus chromium-induced nephrotoxicity in male Sprague-Dawley rat. PLoS One, 10(6)(2015), e0126780, https://doi.org/10.1371/journal.pone.0126780

[12] Ergün. G. \& Aktaș. S. Comparisons of sum of squares methods in ANOVA models. J Fac Vet Med Kafkas Univ, 15(3)(2009), 481-484, https://doi.org/10.9775/kvfd.2009.213

[13] Fujimoto. M., Tsuneyama. K., Fujimoto. T., Selmi. C., Gershwin. ME. \& Shimada. Y., Spirulina improves non-alcoholic steatohepatitis, visceral fat macrophage aggregation, and serum leptin in a mouse model of metabolic syndrome. Dig Liver Dis, 44(9)(2012), 767-774, https://doi.org/10.1016/j.dld.2012.02.002

[14] Gad. AS., Khadrawy. YA., El-Nekeety. AA., Mohamed. SR., Hassan. NS. \& Abdel-Wahhab. MA. Antioxidant activity and hepatoprotective effects of whey protein and Spirulina in rats. Nutrition, 27(5)(2011), 582-589, https://doi.org/10.1016/j.nut.2010.04.002

[15] Gargouri. M., Magné. C. \& El Feki. A., Hyperglycemia, oxidative stress, liver damage and dysfunction in alloxan-induced diabetic rat are prevented by Spirulina supplementation. Nutr Res, 36(11)(2016a), 1255-1268, https://doi.org/10.1016/j.nutres.2016.09.011

[16] Gargouri. M., Ben Saad. H., Ben Amara. I., Magné. C. \& El Feki. A. Spirulina exhibits hepatoprotective effects against lead induced oxidative injury in newborn rats. Cell Mol Biol, 62(10)(2016b), https://doi.org/10.14715/cmb/2016.62.10.14 85-93,

[17] González de Rivera. C., Miranda-Zamora. R., Díaz-Zagoya. JC. \& Juárez-Oropeza. MA. Preventive effect of Spirulina maxima on the fatty liver induced by a fructose-rich diet in the 
rat, a preliminary report. Life Sci, 53(1)(1993), 57-61, https://doi.org/10.1016/0024-3205(93)90611-6

[18] Gupta. S., Hrishikeshvan. HJ. \& Sehajpal. PK. Spirulina protects against rosiglitazone induced osteoporosis in insulin resistance rats. Diabetes Res Clin Pract, 87(1)(2010), 38-43, https://doi.org/10.1016/j.diabres.2009.10.002

[19] Hirata. T., Tanaka. M., Ooike. M., Tsunomura. T. \& Sakaguchi. M. Antioxidant activities of phycocyanobilin prepared from Spirulina platensis. J Appl Phycol, 12(3)(2000), 435-439, https://doi.org/10.1023/A:1008175217194

[20] Hosoyamada. Y., Takai. Y. \& Kato. T. Effects of water-soluble and -insoluble fractions of Spirulina on serum lipid components and glucose tolerance in rats. J Jpn Soc Nutr Food Sci, $\quad 44(4)(1991), \quad 273-277$, https://doi.org/10.4327/jsnfs.44.273

[21] Hosseini. SM., Khosravi-Darani. K. \& Mozafari. MR. Nutritional and medical applications of Spirulina microalgae. Mini Rev Med Chem, 13(8)(2013), 1231-1237, https://doi.org/10.2174/1389557511313080009

[22] Hozayen. WG., Mamoud. AM., Soliman. HA. \& Mostafa. SR. Spirulina versicolor improves insulin sensitivity and attenuates hyperglycemia-mediated oxidative stress in fructose-fed rats. J Intercult Ethnopharmacol, 5(1)(2016), 57-64, https://doi.org/10.5455/jice.20151230055930

[23] Ibrahim. M., Khaja. ZU. \& Narasu. ML. Hepatoprotective activity of Boswellia serrata extracts: In vitro and in vivo studies. Int J Pharm Appl, 2(1)(2011), 89-98.

[24] Iwata. K., Inayama. T. \& Kato. T. Effects of Spirulina platensis on plasma lipoprotein lipase activity in fructose-induced hyperlipidemic rats. J Nutr Sci Vitaminol, 36(2)(1990), 165171, https://doi.org/10.3177/jnsv.36.165

[25] Karkos. PD., Leong. SC., Karkos. CD., Sivaji. N. \& Assimakopoulos. DA. Spirulina in clinical practice: Evidence-based human applications, Evid Based Complement Alternat Med, (2011), 531053, https://doi.org/10.1093/ecam/nen058

[26] Kato. T., Takemoto. K., Katayama. H. \& Kuwabara. Y. Effects of Spirulina (Spirulina platensis) on dietary hypercholesterolemia in rats. J Jap Soc Nutr Food Sci, 37(4)(1984), 323332, https://doi.org/10.4327/jsnfs.37.323

[27] Kumar. N., Singh. S., Patro. N. \& Patro. I. Evaluation of protective efficacy of Spirulina platensis against collagen-induced arthritis in rats. Inflammopharmacology, 17(3)(2009), 181-190, https://doi.org/10.1007/s10787-009-0004-1

[28] Liu. Q., Huang. Y., Zhang. R., Cai. T. \& Cai. Y. Medical application of Spirulina platensis derived C-phycocyanin. Evid Based Complement Alternat Med, (2016), 7803846, https://doi.org/10.1155/2016/7803846

[29] Lee. EH., Park. JE., Choi. YJ., Huh. KB. \& Kim. WY. A randomized study to establish the effects of Spirulina in type 2 diabetes mellitus patients. Nutr Res Pract, 2(4)(2008), 295-300, https://doi.org/10.4162/nrp.2008.2.4.295
[30] Manconia. M., Pendás. J., Ledón. N., Moreira. T., Sinico. C., Saso. L. \& Fadda. AM. Phycocyanin liposomes for topical anti-inflammatory activity: in-vitro in-vivo studies. J Pharm Pharmacol, 61(4)(2009), 423-430, https://doi.org/10.1211/jpp/61.04.0002

[31] Martínez-Sesmero. JM., Bastida. S. \& SánchezMuniz. FJ. Cardiovascular risk and metabolic syndrome at the Toledo Area Study. Nutr Hosp, 24(2)(2009) 167-175.

[32] Mayuren. C., Reddy. VV., Priya. SV. \& Devi. VA. Protective effect of livactine against $\mathrm{CCI}_{4}$ and paracetamol induced hepatotoxicity in adult Wistar rats. N Am J Med Sci, 2(10)(2010), 491495, https://doi.org/10.4297/najms.2010.2491

[33] Miczke. A., Szulińska. M., Hansdorfer-Korzon. R., Kręgielska-Narożna. M., Suliburska. J., Walkowiak. J. \& Bogdański. P. Effects of Spirulina consumption on body weight, blood pressure, and endothelial function in overweight hypertensive Caucasians: a double blind, placebo-controlled, randomized trial. Eur Rev Med Pharmacol Sci, 20(1)(2016), 150-156.

[34] Morsy. MA., Gupta. S., Nair. AB., Venugopala. KN., Greish. K. \& El-Daly. M. Protective effect of Spirulina platensis extract against dextransulfate-sodium-induced ulcerative colitis in rats. Nutrients, 11(2019), 2309, https://doi.org/10.3390/nu11102309

[35] Moura. LP., Puga. GM., Beck. WR., Teixeira. IP., Ghezzi. AC., Silva. GA. \& Mello. MA. Exercise and Spirulina control non-alcoholic hepatic steatosis and lipid profile in diabetic Wistar rats. Lipids Health Dis, 10(2011), 77, https://doi.org/10.1186/1476-511X-10-77

[36] Moura. LP., Gurjão. ALD., Filho. JCJ., Mizuno. J., Suemi. C. \& Mello. MA. Spirulina, exercise and serum glucose control in diabetic rats. Arq Bras Endocrinol Metab, 56(1)(2012), 25-32, https://doi.org/10.1590/s0004-27302012000100005

[37] Pak. W., Takayama. F., Mine. M., Nakamoto. K., Kodo. Y., Mankura. M., Egashira. T., Kawasaki. H. \& Mori. A. Anti-oxidative and anti-inflammatory effects of Spirulina on rat model of nonalcoholic steatohepatitis. J Clin Biochem Nutr, 51(3)(2012), https://doi.org/10.3164/jcbn.12-18

[38] Ramamoorthy. A. \& Premakumari. S. Effect of supplementation of Spirulina on hypercholesterolemic patients. J Food Sci Technol, 33(2)(1996), 124-128.

[39] Sadek. KM., Lebda. MA., Nasr. SM. \& Shoukry. M. Spirulina platensis prevents hyperglycemia in rats by modulating gluconeogenesis and apoptosis via modification of oxidative stress and MAPK-pathways, Biomed Pharmacother, 92(2017), 1085-1094, https://doi.org/10.1016/j.biopha.2017.06.023

[40] Salazar. M., Chamorro. GA., Salazar. S. \& Steele. CE. Effect of Spirulina maxima consumption on reproduction and peri- and postnatal development in rats. Food Chem Toxicol, 34(4)(1996), 353-359, https://doi.org/10.1016/0278-6915(96)00000-2 
[41] Sharma. MK., Sharma. A., Kumar. A. \& Kumar. M., Spirulina fusiformis provides protection against mercuric chloride induced oxidative stress in Swiss albino mice. Food Chem Toxicol, 45(12)(2007)

2412-2419, https://doi.org/10.1016/j.fct.2007.06.023

[42] Statnick. MA., Beavers. LS., Conner. LJ., Corominola. H., Johnson. D., Hammond. CD., Rafaeloff-Phail. R., Seng. T., Suter. TM., Sluka. JP., Ravussin. E., Gadski. RA. \& Caro. JF. Decreased expression of apM1 in omental and subcutaneous adipose tissue of humans with type 2 diabetes. Int J Exp Diabetes Res, $1(2)(2000)$,

81-88, https://doi.org/10.1155/edr.2000.81

[43] Torres-Durán. PV., Paredes-Carbajal. MC., Mascher. D., Zamora-González. J., Díaz-Zagoya. JC. \& Juárez-Oropeza. MA. Protective effect of Arthrospira maxima on fatty acid composition in fatty liver. Arch Med Res, 37(4)(2006), 479483, https://doi.org/10.1016/j.arcmed.2005.08.005

[44] Upasani. CD. \& Balaraman. R. Protective effect of Spirulina on lead induced deleterious changes in the lipid peroxidation and endogenous antioxidants in rats. Phytother Res, 17(4)(2003),

https://doi.org/10.1002/ptr.1135

[45] Vázquez-Velasco. M., González-Torres. L., Méndez. MT., Bastida. S., Benedí. J., GonzálezMuñoz. MJ. \& Sánchez-Muniz. FJ. Glucomannan and glucomannan plus Spirulina-enriched squid-surimi added to high saturated diet affect glycemia, plasma and adipose leptin and adiponectin levels in growing fa/fa rats. Nutr Hosp, 32(6)(2015), 2718-2724, https://doi.org/10.3305/nh.2015.32.6.9936

[46] Vidé. J., Virsolvy. A., Romain. C., Ramos. J., Jouy. N., Richard. S., Cristol. JP., Gaillet. S. \& Rouanet. JM. Dietary silicon-enriched Spirulina improves early atherosclerosis markers in hamsters on a high-fat diet. Nutrition, 31(9)(2015) 11481154, https://doi.org/10.1016/j.nut.2015.03.014

[47] Vonshak. A., Spirulina platensis (Arthrospira): Physiology, Cell-Biology and Biotechnology, London: Taylor \& Francis (1997), https://doi.org/10.1023/A:1012498515734

[48] Wu. Q., Liu. L., Miron. A., Klímová. B., Wan. D. \& Kuča. K. The antioxidant, immunomodulatory, and anti-inflammatory activities of Spirulina: an overview. Arch Toxicol, 90(8)(2016), 18171840, https://doi.org/10.1007/s00204-016-1744-5

[49] Yang. RZ., Park. S., Reagan. WJ., Sargeant. C., Fisher. RA., Luketic. VA., Sterling. RK., Shiffman. ML., Stravitz. RT. \& Sanyal. AJ. Clinical and histologic spectrum of nonalcoholic fatty liver disease associated with normal ALT values. Hepatology, 37(6)(2003), 1286-1292, https://doi.org/10.1053/jhep.2003.50229

[50] Yang. RZ., Park. S., Reagan. WJ., Goldstein. R., Zhong. S., Lawton. M., Rajamohan. F., Qian. K., Liu. L. \& Gong. DW. Alanine aminotransferase isoenzymes: molecular cloning and quantitative analysis of tissue expression in rats and serum elevation in liver toxicity, Hepatology,
49(2)(2009),

https://doi.org/10.1002/hep.22657

598-607,

[51] Yiğit. F., Gürel-Gürevin. E., Işbilen-Başok. B., Esener. OB., Bilal. T., Keser. O., Altiner. A., Yilmazer. N. \& Ikitimur-Armutak. EI. Protective effect of Spirulina platensis against cell damage and apoptosis in hepatic tissue caused by high fat diet. Biotech Histochem, 91(3)(2016), 182194, https://doi.org/10.3109/10520295.2015.1114142

[52] Zeinalian. R., Farhangi. MA., Shariat. A. \& Saghafi-Asl. M. The effects of Spirulina platensis on anthropometric indices, appetite, lipid profile and serum vascular endothelial growth factor (VEGF) in obese individuals: a randomized double blinded placebo controlled trial. BMC Complement Altern Med, 17(1)(2017), 225, https://doi.org/10.1186/s12906017-1670-y

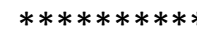

